\title{
A leitura como prática social \\ a partir da enunciação de narrativas de vida: um estudo de caso com uma professora pedagoga
}

Francisco Rogiellyson da Silva Andrade

Universidade Federal do Ceará

rogiellyson@yahoo.com.br

Priscila Sandra Ramos de Lima

Universidade Federal do Ceará

priscila-sandra@hotmail.com

Dannytza Serra Gomes

Universidade Federal do Ceará

dannytzasg@gmail.com

\section{Resumo}

Este trabalho analisa uma narrativa de vida enunciada por uma professora pedagoga. A base teórica advém dos estudos do letramento, endossados nas práticas sociais de escrita (STREET, 2014) e nos pressupostos interacionais de leitura (SILVA, 1999; KOCH; ELIAS, 2012; BAKHTIN/VOLOCHÍNOV, 2006). A metodologia se ancora na etnossociologia clínica proposta por Andrade (2019), que, por sua vez, adota os pressupostos de Vasconcelos (2005) ao defender a narrativa de vida como dispositivo metodológico que permite a horizontalidade entre pesquisador e participante, conferindo a este maior protagonismo em sua enunciação. A análise da narrativa aponta a interpretação de que a participante experienciou a leitura como prática social, pois as várias instituições em que se engajou exigiram dela demandas leitoras. Por isso, em sua atuação docente, ela procura construir com os estudantes habilidades concernentes à prática social da leitura, a fim de que também eles possam se engajar responsivamente em instituições sociais. Desse modo, percebe-se que a narrativa de vida, como mecanismo de autoformação, propicia uma projeção de si do narrador que demonstra a vinculação de sua experiência com sua atuação praxiológica.

Palavras-chave: Práticas sociais de leitura. Narrativas de vida. Concepções de leitura. Etnossociologia Clínica. 


\begin{abstract}
This work analyzes a narrative of life enunciated by a pedagogical teacher. The theoretical basis comes from the studies of literacy, endorsed in the social practices of writing (STREET, 2014) and in the interational assumptions of reading (SILVA, 1999; KOCH; ELIAS, 2012; BAKHTIN/VOLOCHÍNOV, 2006). The methodology is anchored in the clinical ethnosociology proposed by Andrade (2019), who, in turn, adopts the assumptions of Vasconcelos (2005) by defending the narrative of life as a methodological device that allows horizontality between researcher and participant, giving this greater protagonism in its enunciation. The analysis of the narrative points to the interpretation that the participant experienced reading as a social practice, since the various institutions in which he or she engaged demanded reading demands of it. For this reason, in her teaching, she seeks to build with students skills concerning the social practice of reading, so that they too can engage responsibly in social institutions. In this way, it is perceived that the narrative of life, as a mechanism of self-training, provides a projection of the self of the narrator who demonstrates the link of his experience with his praxeological performance.

Keywords: Social reading practices. Life narratives. Concepts of reading. Clinical ethnosociology.
\end{abstract}

\title{
1 Introdução
}

Silva (1999) considera que a maneira como um sujeito experiencia determinado processo influencia nas representações que ele faz disso na prática. Assim, ainda que atualizando crenças e concepções, nossas práxis pedagógicas, por exemplo, sempre são um reflexo daquilo que experienciamos.

No que se refere à profissão docente, Andrade, Lima e Serra (2020) defendem que a formação inicial e continuada tem o potencial de ressignificar crenças de professores acerca do ensino de leitura. Na pesquisa dos autores, docentes que experienciaram a leitura sob óticas redutoras do ato de ler (SILVA, 1999), ao se colocarem num processo de formação pautado em narrativas de vida, ressignificaram suas experiências, afirmando adotar metodologias mais voltadas para uma prática de leitura numa perspectiva interacionista (SILVA, 1999; KOCH; ELIAS, 2012).

Percebendo o potencial das experiências para a formação docente, neste artigo, analisa-se uma narrativa de vida enunciada por uma professora pedagoga. Hipotetizamos, com base nos achados de Andrade, Lima e Serra 
(2020), que, ao ter a oportunidade de projetar narrativamente seu processo formativo e sua práxis pedagógica, a professora articula saberes que evidenciam, na e pela linguagem narrativamente discursivizada, suas concepções de leitura.

Com esse objetivo, afora esta introdução e as considerações finais, a seguir, apresenta-se o tópico de fundamentação teórica. Após, realiza-se a descrição dos pressupostos e dos passos metodológicos que viabilizam a coleta e a análise dos dados. Por fim, faz-se a análise da narrativa de vida da professora.

\section{A leitura como prática social}

A leitura, por ser fenômeno articulado a capitais sócio-históricoculturais, é sempre ancorada sob a lógica dos usos que os sujeitos fazem dela. Em Andrade (2019), entende-se que não se pode pensar a leitura na medida do verbo ser, mas na do verbo estar. Significa dizer que não é possível definir o ato de ler a partir de amarras teóricas, pois, na dinâmica das interações, ocorre sempre uma atualização única e irrepetível de sua funcionalidade, o que evidencia uma pluralidade de concepções e crenças acerca do processo de leitura.

Nesse aspecto, interessa-nos aqui entender como a leitura é percebida sob a lente de teorias que a entendem como prática social, ou seja, como maneira de engajamento, atuação, circulação e construção de poder/autoria em situações de que os sujeitos participam com o fito de serem reconhecidos como integrantes de determinada formação social-discursiva.

Adotando essa lente, Koch e Elias (2012) defendem que a leitura é um processo no qual o texto medeia a interação entre autor e leitor, de modo que estes dialogicamente constroem os sentidos do texto. Nessa perspectiva, enquanto o produtor revela discursos e ideologias por meio de escolhas linguísticas e estruturas gramaticais, o leitor recupera esses construtos com vistas à compreensão. Assim, a leitura é percebida como interação, o texto como o lugar onde se dá esse processo, em que aspectos sociais e discursivos se imbricam.

Nessa dimensão, a leitura é vista como um processo que leva em consideração as intenções do autor, os elementos linguísticos por ele utilizados, mas também "[...] as experiências e os conhecimentos do leitor" 
A leitura como prática social a partir da enunciação de narrativas de vida...

(KOCH; ELIAS, 2012, p. 11), bem como discursos e ideologias evocados pelos construtos sócio-históricos em que se circunscrevem os sujeitos.

Silva (1999), em filiação a essa discussão, diz que: ler é interagir, pois o leitor interage com o autor, de modo a confirmar e refutar informações; ler é produzir sentidos, pois os leitores produzem sentidos ao que leem, de modo que o sentido não é único e estável, mas modelável; ler é compreender e interpretar, pois, ao ler, o leitor realiza um projeto de compreensão que se realiza num processo de interpretação, ou seja, "o processo de interpretação demarca a abordagem do texto pelo leitor de modo que a compreensão vá se constituindo ao longo da leitura em si" (SILVA, 1999, p. 17).

Nessa ótica, a leitura passa a ser vista como um processo pelo qual texto e leitor, à medida que interagem, se transformam cooperativamente. Isso provoca a percepção de que o foco da interação leitora está no encontro entre texto e leitor, o que resulta em um novo evento, uma vez que "o significado é sempre uma relação entre o texto e o contexto (sócio-históricocultural) e não existe à parte da interpretação de alguém daquela relação" (BRAGGIO, 1992, p. 69).

Visto assim, o ato de ler revela protagonismo do leitor, pois é ele quem traz a bagagem pela qual transformará o texto e irá se transformar via leitura. Segundo Braggio (1992), a leitura exige um "leitor crítico que, de posse da linguagem escrita, seja sujeito de sua práxis" (BRAGGIO, 1992, p. 94). Partindo disso, evita-se o perigo de se cair no que a autora chama de uma concepção de leitor ingênuo, que seria aquele que entende que a linguagem é monovalente e apenas repete discursos, crenças e valores da classe dominante, sem criticá-los.

Dessa maneira, ancorando-se na proposta bakhtiniana sobre interação, é preciso alcançar uma atitude responsiva do leitor, a qual, inclusive, é requerida pelo produtor de texto. Este, a partir da manifestação de sua individualidade e de sua visão de mundo, realiza uma influência didática sobre o leitor, a fim de levá-lo à adesão dos discursos mobilizados pelo texto. Nesse construto, as palavras do autor ressoam dialogicamente com as visões de mundo do leitor e provocam a transformação deste.

Assim, o que ocorre é um processo de réplica. Bakhtin/Volochínov (2006, p. 135, grifos do autor) define ser a compreensão uma forma de diálogo, pois, segundo ele, "Compreender é opor à palavra do locutor uma contrapalavra". Sendo a compreensão uma das maneiras por que se realiza 
o diálogo, o ato de compreender se concretiza no espaço de tensão discursivo-ideológico em que se efetua a enunciação.

A partir disso, interpretamos que a leitura é endossada tal como teoriza Bakhtin/Volochínov (2006), pois é uma interação eivada de tensões fundadas sob os diálogos discursivos emergentes da enunciação. Como defende Andrade (2020), essa percepção de leitura está na base da proposta dos estudos do letramento, que defendem que as atividades mediadas pela escrita são uma prática social. Isso significa dizer que as interações se dão em sociedade, ou seja, em contextos socialmente legitimados e que discursivamente se delineiam.

Nesse sentido, Street (2014) afirma ser necessário pensar o letramento como uma prática ideológica. Nessa proposta, as situações de leitura são vistas como construções permeadas de sentidos culturais. $\mathrm{O}$ letramento, portanto, deixa de ser uno e passa a ser visto a partir de uma pluralidade de práticas, já que se modela em função de diferentes mecanismos de constituição. A questão ideológica, como afirma Street (2014), permite entrever não somente a introdução de sentidos discursivos e culturais nas práticas letradas, mas também que relações de poder/autoridade se apresentam e se consolidam via escrita.

Portanto, a concepção do autor, à qual também se vinculam os pressupostos bakhtinianos, é a de que a escrita nunca é neutra, mas sempre evoca, reproduz e refrata discursos. Em função disso, o ensino da leitura deve levar em consideração aspectos identitários, discursivos, histórico-culturais, ideológicos e contextuais. Isso se deve justamente por Street (2014) se inserir numa perspectiva etnográfica de letramento, o que significa dizer que é necessário entender as necessidades dos sujeitos nas práticas de letramento da sua cultura, ao invés de levar em consideração um modelo ocidental e elitizadamente homogeneizante.

Segundo Street (2014), a sociedade relegou à escola o dever de formar leitores, o que criou a representação de uma prática escolar de leitura, a única correta e socialmente aceita. A fim de medir a aprendizagem, constroem-se maneiras consideradas corretas de interpretação dos textos, de modo que os aprendizes não podem se afastar delas sob pena de serem taxados como iletrados.

De encontro a isso, é preciso perceber a leitura como uma prática social e, sendo assim, mesmo que seu ensino esteja vinculado à escola, sua realização se dá em sociedade e sua importância se revela a partir do 
engajamento dos sujeitos nas diferentes instituições de que participam. Dessa maneira, interpretamos que são também as interações externas à escola que tornam a leitura prática significativa no cotidiano dos sujeitos. Assim, como sintetiza Kleiman (2010), as práticas sociais são o ponto de partida e de chegada do processo de ensino da leitura, tendo em vista que é delas que emergem as necessidades de interação mediadas por gêneros discursivos.

Sob essa ótica, concordamos que as práticas de leitura são atividades eminentemente sociais e que precisam ser aprendidas dentro de construções que lhes conferem significado tal como se erigem, se se tem o fito de formar sujeitos capazes de interagir em diferentes situações interacionais das quais desejam participar.

\section{Metodologia}

Esta pesquisa se insere no programa teórico-metodológico indisciplinar da Linguística Aplicada (LA) (MOITA-LOPES, 2006), o qual objetiva problematizar questões concernentes às práticas sociais, as quais têm como materialidade simbólica de significação a linguagem.

Em função de se interessar pelo funcionamento discursivo das práticas de linguagem, a LA é indisciplinar porque entende a necessidade de não se fixar em moldes teóricos e disciplinares para analisar o objeto, articulando saberes concernentes a diferentes campos de estudo na tentativa de responder às demandas plurais emergentes das práticas sociais.

Sob essa orientação, entendemos que o processo de formação do professor, inicial ou continuado, deve se pautar numa metodologia horizontal e alteritária entre conhecimento teórico e práxis pedagógica. Nessa orientação, Josso (2010) afirma que as narrativas de vida, materialidades enunciativas por meio das quais os sujeitos narram episódios vinculados a uma dada experiência, são dispositivos metodológicos capazes de auxiliar os sujeitos a ressignificar e ratificar crenças, uma vez que, ao passar por um processo metacognitivo de seleção de saberes, o narrador, à medida que narra, também analisa experiência, revelando seu olhar reflexivo acerca do saber da experiência, o que gera, em maior ou menor medida, um processo (auto)(trans)formativo que reverbera na práxis.

Vasconcelos (2005), ao encontro disso, considera que a possibilidade de narrar a vida confere aos narradores a oportunidade de 
enunciar saberes que sequer eles próprios possivelmente acreditavam ter. Assim como na prática de formação, também a pesquisa que adota a narrativa de vida como material de análise pressupõe uma postura horizontal do pesquisador frente ao sujeito, já que, ao invés de encontrar evidências teóricas nas falas deste, interessa ao analista coletar saberes construídos e cooperativamente compartilhados pela narração da vida.

Desse modo, esta pesquisa utiliza a etnossociologia clínica (ANDRADE, 2019) como amparo para o processo de geração e análise dos dados. Interessa-nos, por isso, uma temática sociológica, a da leitura, na medida em que ela foi experienciada e é metodologizada por professores responsáveis por seu ensino. $\mathrm{O}$ adjetivo clínica se refere à postura horizontal do analista frente aos dados, objetivando encontrar, por isso, possibilidades interpretativas do discurso narrativamente produzido pelo narrador. Nessa dimensão, a etnossociologia clínica, conforme Andrade (2019), se fixa como proposta metodológica qualitativa de análise, no âmbito dos estudos de caso.

Assim, entrevistamos uma professora pedagoga que, à época da entrevista, tinha 23 anos de experiência e, naquele momento, era professora com vínculo efetivo em duas secretarias de educação. Numa delas, atuava com 7 horas/aulas em uma turma de Educação Infantil V e com 6 horas/aula em uma turma de terceiro ano dos anos iniciais do Ensino Fundamental, sendo responsável, nesta última, pelas disciplinas de história e geografia; no outro vínculo, em decorrência de problemas nas pregas vocais, a professora foi readequada para atuar como responsável pelo funcionamento da biblioteca da escola.

Neste estudo, adotamos o nome-fantasia Ana para nos referir à participante. Sob a condição de ter sua identidade protegida e após ter assinado o termo de consentimento livre e esclarecido, a docente concedeunos uma entrevista narrativa de 49 minutos e 57 segundos. Adotando os pressupostos de coleta assumidos por Vasconcelos (2005), formulamos as seguintes questões-guia para impulsionar a narrativa da professora:

- Conte para mim como foram suas primeiras experiências de leitura.

- Após a infância, houve momentos marcantes seus com a leitura?

- De que maneira as experiências narradas por você influenciam ou influenciaram na sua atuação docente?

- Conte como foram suas experiências com a leitura ao longo da vida. 
Tais pontos foram apenas um norte. Como aponta Vasconcelos (2005), uma vez que, na entrevista narrativa, quem guia a conversa é o próprio sujeito, cabe ao pesquisador realizar uma escuta atenta aos sentidos que o participante constrói em sua fala.

Após isso, fizemos, com base em Vasconcelos (2005), a transcrição simples da entrevista, para que pudéssemos analisar as possibilidades interpretativas apontadas pela narração da professora. Para isso, também nos apoiamos na vertente clínica, que, segundo Vasconcelos (2005), deve se pautar em dois princípios: ausculta e deontologia. Aquele se refere ao fato de o analista buscar as mais profundas interpretações discursivamente elaboradas na narrativa, sem, contudo, superinterpretar o que foi dito pelo sujeito, o que se refere à deontologia.

Segundo essa lógica, a etnossociologia clínica, no processo de análise, se pauta na base hermenêutica, filiando-se à análise do conteúdo veiculado pela narrativa de vida. Ao longo de todo o processo analítico desta pesquisa, interessou-nos as experiências de formação e de práxis de leitura narradas pela docente que discursivizavam uma concepção de leitura como prática social. A análise desse material ocorre a seguir.

\section{Análise da narrativa de vida}

Ana inicia sua narração falando do gosto que sempre teve pela leitura:

Excerto 1. Acerca das práticas iniciais de leitura.

Eu sempre gostei de ler. Desde criança, eu gostava de ler livros paradidáticos, as revistinhas, gibis. Depois, eu entrei no curso Normal pra professor, a gente precisou ler os romances, as crônicas, os contos, as poesias. Então, a leitura faz parte da nossa vida, né? Depois de profissional, pro curso de Pedagogia, tive que ler os estudiosos, e aí continuar lendo, né? Revista, jornal... E hoje em dia eu só leio o que me agrada. [...] Eu já fui tão obrigada a ler tanto [...] que hoje eu gosto mais é de romance e poesia. Na minha infância, [...] a escola que tinha os livros, porque eu não tinha. [...] nós não tínhamos condições de comprar livros, de ter livros, [...] o mundo da leitura sempre foi na escola. Depois, na adolescência, é que eu comecei a comprar alguma coisa e continuava lendo na 
escola. Aí hoje não. Hoje eu sou assinante de jornal, de revista, eu gosto de ler, mas antigamente era na escola, pela influência do professor [...]. Tinha o dia da leitura, reunia todos numa roda... Eu me lembro bem que a professora [...] contava a história, levava o livro e cada um pegava o livro pra ler.

Ana já demonstra que, apesar da falta de recursos, sempre teve interesse pelo universo da leitura, nas diferentes fases da vida. A professora reforça ainda que, para ela, a leitura faz parte do nosso cotidiano, ou seja, segundo conta, o ato de ler é intrínseco às diversas atuações sociais, profissionalmente ou não. Chama atenção, ainda, a ideia que emerge da narração sobre a sociedade, historicamente, ter conferido à escola a responsabilidade pelo incentivo e pela formação de leitores. Como Foucambert (1994) afirma, ainda se pensa que a escola é o espaço único de construção da leitura, o que se configura como empecilho para a melhora da formação leitora dos sujeitos, porque tal formação, segundo o autor, é de responsabilidade conjunta, devendo ser tomada pelas diferentes instituições sociais.

Ao encontro disso, Street (2014) afirma que essa visão de que a escola é a única responsável pela formação leitora resulta no privilégio de um letramento que se centra em habilidades específicas para o espaço escolar, desprestigiando o fato de que há, em cada esfera social, maneiras efetivas e significativas de ler.

Tal interpretação se confirma quando Ana narra que somente na escola podia ter acesso a livros e/ou a materiais de leitura. Ou seja, não havia, a seu tempo, como ainda não há hoje, espaços de compartilhamento de textos escritos, pois, como assevera Foucambert (1994), ainda é necessário que a elite domine esses materiais, de modo a não dar às massas o conhecimento para questionar o poder das camadas dominantes.

Ao pormenorizar isso, Ana confirma que, apesar de ter um espaço familiar que incentivava a leitura, seus recursos eram esvaziados para um acesso mais significativo à cultura escrita.

Excerto 2. Acerca das condições financeiras.

[...] se passasse uma pessoa na porta vendendo enciclopédia, [...] [minha mãe] passava quase um ano pagando, tirando de alguma coisa de dentro de casa [...]. Os presentes que [o papai] dava pra 
gente [...] era livro. Não dava boneca, carro, essas coisas não. Eu gostava, acho que foi por isso que eu me interessei. E eu lia todos [...]. [...] o papai só dava era livro, história em quadrinho. Nem eram novos, eram usados [...].

Mesmo inserida nessa realidade, parece que as experiências por que Ana passou foram importantes o bastante para que percebesse a necessidade da leitura ao longo da vida. Essa construção, inclusive, contribuiu para que se engajasse em grupos sociais diferentes dos da escola:

Excerto 3. Acerca das práticas não-escolares de leitura.

Depois [da escola], eu li muito peça de teatro, porque [...] eu passei 10 anos no grupo de teatro aqui do bairro. [...] a gente lia muito peça de teatro pra escolher o melhor texto e fazer as cenas. $\mathrm{O}$ meu irmão era o coordenador, a minha cunhada escreve livros e história.

A partir disso, podemos inferir que a leitura, na vida de Ana, não ficou restrita à esfera escolar. A professora pôde perceber que o ato de ler era necessário a outros espaços sociais pelos quais ela se interessava. Conforme salientam Kleiman (2010), Street (2014), Soares (2008) e Foucambert (1994), a leitura é uma prática social, o que significa dizer que é uma atividade intrínseca a várias instituições sociais, as quais constroem maneiras específicas de significar a escrita.

Além da própria escola, Ana pôde experimentar a necessidade da leitura em um ambiente livre de concepções dominantes do que vem a ser leitura e que, em alguns casos, limitam/regulam a compreensão (STREET, 2014). Certamente, a maneira de ler, ou seja, de avaliar o que vem a ser um bom texto teatral, no contexto de um grupo de teatro, é uma habilidade diferente daquela requerida pela escola, de modo que outras competências foram necessárias para que a professora pudesse atuar nesse espaço.

Além da esfera escolar e teatral, Ana narra a importância da leitura para sua profissão e para sua fruição, tanto na vida adulta quanto na adolescência: 
Excerto 4. Acerca das preferências de leitura.

Hoje, eu leio romances e leio os livros que são necessários pra nossa profissão. Sempre... É importante ler, você estar sempre se atualizando das coisas. Mas, o romance, é porque eu gosto [...]. Eu sou romântica. Gosto de casos de amor. Eu lia muito... [...] depois da adolescência, o que me marcou muito, eu tinha vários, vários, eu não tinha dinheiro pra comprar, mas eu trocava com as amigas e às vezes eu ia nas bancas de revista e comprava aquelas revistas já usadas: Sabrina, Joulie... Os romances, que era os livrinhos grossos de romance. Não é daqui do Brasil, não, era romances estrangeiros. Eu lia bastante. Porque eu era... Eu não sou romântica nas minhas ações, mas eu gostava de romance, história de castelo, de princesa.

Da mesma maneira que os trechos anteriormente analisados, também aqui Ana reforça a necessidade da leitura para outras esferas sociais, diferentes da escola, inclusive salientando habilidades diferentes das privilegiadas pelos ambientes educacionais. Neste último trecho, a narradora salienta a satisfação que sente em suas leituras pessoais, realizadas por entretenimento, além do próprio fato de ter sido o universo da leitura uma maneira de aproximação das amigas. Também, no início do trecho, a professora fala da importância da leitura para o seu desenvolvimento e atualização profissional.

No contexto disso, percebemos que, para Ana, em sua narrativa, a leitura é discursivamente elaborada como prática social, pois a narradora ressalta as funções sociais que teve o ato de ler nas diferentes fases de sua vida e nos vários ambientes em que atuou/atua. Sob essa lente conceptiva, ao longo de sua narração, Ana comenta acerca das várias habilidades de que necessitava para poder se engajar na dinâmica dos grupos de que participou.

No que se refere à narração de sua práxis, Ana, assim como em sua narrativa de experiências, constrói a leitura como prática social. Segundo a narradora,

Excerto 5. Acerca da influência das experiências na práxis. Esse prazer pela leitura, essa vontade de ler e mostrar para os alunos que é importante a leitura, fez com que eu fizesse isso com eles. Até hoje, mesmo sendo professora de História e Geografia [...], eu trabalho muito com livros. [...] levo meus alunos pra 
biblioteca; lá, eles escolhem os livros. [...] O meu gostar de ler influencia para que eles também leiam. Aí, no Infantil, todo dia eu conto uma história, todo dia que eu entro na sala, eu conto uma história pra eles. Não é todo professor que conta uma história todo dia. [...] na acolhida, eu boto as historinhas pra eles fazerem a leitura visual, a leitura só pelas imagens, mesmo sem saber ler, que é o infantil V. Então, acho que a leitura faz parte da vida da gente. Os meus afilhados, meus sobrinhos que frequentam a minha casa, né, eu botava pra ler.

Como descrito em nossa metodologia, Ana, à época da entrevista, era professora de história e geografia do terceiro ano do Ensino Fundamental e da Educação Infantil V. Além disso, a professora, no outro vínculo efetivo que possui, atuava na biblioteca, auxiliando na organização e no incentivo à frequência desse espaço. Nessa conjuntura profissional, em seu discurso narrativamente elaborado sobre sua práxis, mesmo hoje não mais atuando como professora de Língua Portuguesa, Ana conta que procura evidenciar aos alunos que a leitura deve ser uma prática, o que significa dizer, segundo sua narração, que cabe a eles identificar momentos em que precisam se valer da leitura para poder interagir socialmente. Inclusive, quando a narradora afirma "[...] mesmo eu sendo professora de História e Geografia [...]", o uso da conjunção concessiva evidencia, conforme Mustifaga e Goettms (2008), que se tem a crença de que o aprimoramento da leitura e da construção do letramento são responsabilidades únicas do professor de Língua Portuguesa.

Mesmo demonstrando tal crença, Ana afirma que vai de encontro a isso, uma vez que, por considerar a leitura como prática social, em todos os campos de atuação, o ato de ler está presente, seja como maneira de engajamento seja como maneira de ascensão. Dessa forma, consoante Mustifaga e Goettms (2008), cabe a todos os professores, não somente os de línguas, desenvolver habilidades de leitura que satisfaçam o acesso ao conhecimento de cada campo do saber, justamente porque, conforme Street (2014), Kleiman (2010) e Soares (2008), cada esfera discursiva constrói maneiras próprias de desenvolver a escrita e o acesso a ela, considerando aí as culturas disciplinares de cada campo, a metalinguagem e a disposição das informações de cada gênero discursivo, portanto as maneiras de interagir pela escrita nas diferentes esferas sociais.

Além de narrar sobre sua experiência como professora no eixo de alfabetização, Ana também narra acerca de sua práxis na Educação Infantil. 
Uma importante consideração é quando ela conta que, já nesse momento, em que ainda não se preconiza pelo contundente contato com a escrita, a professora procura construir momentos de apego à leitura, priorizando, com os alunos, a leitura visual. Em acordo com Foucambert (1994), a leitura, certamente, é uma maneira verbal de interagir, mas, ao contrário da fala, aquela é uma linguagem para os olhos. Em razão disso, segundo o mesmo autor, devemos construir novas habilidades de interação com o fito de que os estudantes tenham acesso à cultura escrita: esta é eminentemente visual, e não acústica, como a fala.

Nesse contexto, Ana, narrativamente, parece concordar com essa percepção no que se refere ao fato de evidenciar aos estudantes que a escrita tem natureza diferente da fala e que, nessa medida, importante não é oralizar o que está escrito, já que isso seria habilidade secundária. Conforme pesquisa realizada por Serafim e Cordeiro (2013), essa leitura visual auxilia o leitor na produção de inferências e de hipóteses acerca do que trata o material verbal. Se assim o é, como explana Silva (1999), Ana, ao narrar que prioriza o contato visual dos alunos com os textos escritos, leva à inferência de que oportuniza que eles realizem predições, confirmem e/ou refutem hipóteses, confrontem posicionamentos e visões de mundo e conversem entre si sobre suas opiniões, habilidades importantes no que se refere à leitura e à interação mediada pela escrita. Além disso, ainda com base no que se pode depreender da narrativa de Ana, seus estudantes, ainda em tenra idade, começam a construir a ideia de que os textos não são categorias exclusivamente verbais, mas que também são formados por outras semioses, que contribuem para a construção dos sentidos, como cores, imagens, expressões faciais, disposição das palavras.

Após narrar suas experiências como professora regente num dos vínculos efetivos que possui, a professora conta como incentiva a leitura na outra escola onde trabalha, onde é lotada na biblioteca de uma escola de ensino médio.

Excerto 6. Acerca das experiências como responsável por uma biblioteca.

[...] trabalho numa biblioteca. Lá, é difícil de incentivar, são mais velhos. Agora, a gente percebe que eles só leem se for o professor que manda, se for pra fazer um trabalho. Agora, há exceção. Acho que o meu caso, eu fui uma exceção, que a maioria dos jovens realmente não gostavam de ler, mesmo quando eu era jovem. [...] 
eu vejo hoje os que gostam, que entram, que pegam o livro pra ler, e os que não pegam. Aí o que é que eu faço? [...] escolho alguns livros e coloco em cima da mesa, uma revista, um jornal, um livro, [...] pra, quando eles se interessarem a entrar lá na biblioteca, pegar um livro. Ou entra uma pessoa, eu digo "Olha, ali, tem literatura juvenil; ali, tem interessante pra vocês; ali, é contemporânea, estrangeira". Tô sempre falando. [...] nós ganhamos 80 livros novos, né. Foi doações que a coordenadora conseguiu. Esse que eu tô lendo é de lá da mesa que eu peguei: "A culpa é das estrelas", nesse estilo deles. Aí nós colocamos na mesa e colocamos o cartaz: "Livros novos. Alugue." Então, desses novos, só tem 15. O resto, foram alugados. Foram procurados. Eu acho que, hoje em dia [...], o professor de Português, estão tão absorvidos de dar coisas novas, de acompanhar a tecnologia, que estão um pouco esquecidos de levá-los até a biblioteca, de levar a eles os livros e fazer esse serviço mesmo de cobrar, como a gente fazia antigamente. Através do contato com o livro, querendo ou não querendo, né, você vai ler e você vai dizer assim: "É isso mesmo que eu quero? Não, não quero. Não gosto de ler". Eu acho que o professor precisa insistir nisso, porque, se deixar eles livres, não lê. Eu acho lindo o trabalho de alguns professores que têm ali, elas sempre estão levando os livros pros alunos, fazem um trabalho com os livros, com contos, já fizeram com contos, fizeram com poesias, fizeram com crônicas, porque o adolescente, ele não pega gosto por ler, não. Ele só vai ter aquele gosto pra leitura, se ele tiver o contato, a primeira experiência. E tendo aquele incentivo ou cobrando por nota, naquele momento, ele tá tendo aquele contato. Depois, ele vai descobrir se ela vai querer continuar ali, indo ou não.

Ao contar sobre a experiência de ser lotada numa biblioteca, a professora relata o fato de ser mais difícil, em função da idade, promover o apego à leitura entre os adolescentes. Tal afirmação nos remete ao fato de, certamente, a professora ainda priorizar os suportes físicos de escrita, valorizando estes em detrimento dos já onipresentes suportes virtuais. Mesmo assim, Ana, segundo conta, tenta incutir nesses estudantes, já na segunda etapa da adolescência, a importância do acesso à cultura letrada, como maneira de conhecer o passado da sociedade e da própria comunidade. Muitas vezes, esse passado está narrado nos inúmeros volumes das bibliotecas (FOUCAMBERT, 1994). 
Do mesmo modo, Ana narra que, ao receber doações de livros novos e mais atuais, os estudantes começaram a esvaziar a prateleira em que se encontravam essas obras. Essa evidência mostra a importância do que diz Freire (2003) acerca do diálogo entre a leitura do mundo e a leitura da palavra. Os livros a que se refere a professora não somente são famosos hodiernamente, mas também abordam conflitos e experiências que, nessa fase, vivenciam os adolescentes. Nesse contexto, por preconizar a leitura de livros clássicos (SILVA, 1999), os estudantes, muito possivelmente, entendem o ambiente da biblioteca como um espaço que não os contempla.

Além disso, Ana reclama das pressões sociais existentes em cima dos professores de língua materna, que, em razão disso, ao invés de oportunizar ambientes de leitura como prática social e de permitir aos alunos a construção de suas preferências de leitura, dão ênfase tão somente a um letramento autônomo (STREET, 2014), o que, segundo a análise de Braggio (1992), Foucambert (1994), Soares (2008) e Street (2014), tem como consequência a formação de analfabetos funcionais, os quais não percebem a circulação ideológico-discursiva concernente às práticas de linguagem.

A partir dessa análise, consideramos que, da mesma forma como a narrativa de experiência, também a narrativa de práxis de Ana empreende, na e pela linguagem, a inferência de que a professora concebe a leitura como prática social, considerando que ela narra acerca da importância do acesso à leitura em diferentes momentos da vida e esferas de discurso, bem como deixa entrever que é necessário construir com os alunos habilidades de leitura e, também, maneiras de se engajar nos diferentes espaços sociais.

Segundo analisamos, a narração da professora endossa o discurso de que o ato de ler se erige a partir das práticas plurais que o circunscrevem. Nesse contexto, necessário se faz evidenciar habilidades que valorizem a leitura como uma linguagem para olhos e, além disso, que haja uma corresponsabilidade entre os atores sociais na promoção do acesso a ela.

A partir disso, podemos realizar nossas considerações finais acerca de nossa análise. A seguir, apresentamos isso, apontando as possíveis hipóteses que podem ser construídas com base no que se pôde inferir pela análise da narrativa de Ana. 
A leitura como prática social a partir da enunciação de narrativas de vida...

\section{Considerações finais}

Este trabalho objetivou analisar a construção da leitura como prática social via narrativa de vida de uma professora pedagoga. A base teórica abalizadora foi a das concepções sociais e interacionais de leitura. Metodologicamente, amparou-nos a etnossociologia clínica, como perspectiva qualitativa e interpretativa, centralizando a narrativa de vida como dispositivo de coleta, análise e autoformação docente.

A análise da narrativa de vida permitiu a interpretação de que Ana, a professora narradora, experienciou a leitura nas diferentes instituições sociais de que participou ao longo da vida, inclusive como maneira de entretenimento. Ao longo dessas experiências, a professora necessitou mobilizar diferentes estratégias para se engajar nas práticas leitoras dessas instituições.

Com base nisso, segundo o discurso narrativamente elaborado pela professora, pudemos inferir que as experiências de Ana auxiliaram-na a adotar metodologias em sua práxis pedagógica que viabilizassem uma postura de seus alunos semelhante à que a professora desenvolveu ao longo da vida. Nessa ótica, percebemos como a narrativa é um mecanismo de autoformação do profissional docente, já que, ao longo desse processo enunciativo, o narrador seleciona saberes que emergem de sua experiência, operacionalizando discursos que o permitem catalisar crenças que viabilizam seu fazer pedagógico sob a concepção ideológica emergida narrativamente.

Assim, concebendo, via narrativa de vida, o ato de ler como prática social, Ana entende que a leitura se desenvolve dentro de práticas plurais que constituem as interações verbais em sociedade. Isso posto, é necessário, segundo sua narrativa, que os sujeitos desenvolvam habilidades que os permitam a construção de maneiras pelas quais consigam interagir nos diferentes ambientes em que se engajam.

Além disso, a narrativa salienta que a escrita, em função de ser uma linguagem para os olhos, deve ser tratada de tal forma, considerando aí, também, a produção de inferências e a confrontação de ideias, visando um projeto de compreensão estabelecido desde a seleção dos objetivos de leitura. Ainda nesse âmago, a narrativa permite inferir que não somente ao ensino de língua materna cabe a construção dessas habilidades, mas a todas as disciplinas, bem como às múltiplas esferas sociais. 
Sob esse amparo, defendemos que o uso de narrativa de vida é eficaz como método de pesquisa e de (trans)(auto)formação docente, pois permite que o próprio sujeito se posicione frente ao que sabe e ao que lhe é imposto, permitindo uma tomada de decisão nesse espaço tensivo de discursos que lhe circunscrevem. Nessa medida, a narrativa de vida é um dispositivo enunciativo que viabiliza uma formação inicial e continuada do professor mais alteritária e horizontal.

\section{Referências}

ANDRADE, F. R. da S. Autoconceitos de leitura erigidos a partir de narrativas de vida de professores alfabetizadores. 2019. 192f. Dissertação (Mestrado) - Universidade Federal do Ceará, Departamento de Letras Vernáculas, Programa de Pós-Graduação em Linguística, Fortaleza, 2019.

ANDRADE, F. R. da S. A leitura à luz do Círculo de Bakhtin: uma proposta dialógico-interacionista. Línguas e Letras, Cascavel, v. 21, n. 49, p. 48-66, 2020 .

ANDRADE, F. R. da S.; LIMA, P. S. R. de; SERRA, D. G. A ressignificação do ensino de leitura propiciada pela formação docente: um estudo de caso a partir de narrativas de vida. Fólio: Revista de Letras, v. 12, n. 1, jul. 2020.

BAKHTIN, M. (VOLOCHÍNOV). Marxismo e filosofia da linguagem. Tradução de Michel Lahud e Yara Frateschi Vieira. 12. ed. São Paulo: Huditec, 2006.

BRAGGIO, S. L. B. Leitura e alfabetização: da concepção mecanicista à sociopsicolinguística. Porto Alegre: Artes Médicas, 1992.

FREIRE, P. A importância do ato de ler: em três artigos que se completam. São Paulo: Cortez, 2003.

FOUCAMBERT, J. A leitura em questão. Tradução de Bruno Charles Magne. Porto Alegre: Artes Médicas, 1994. 
A leitura como prática social a partir da enunciação de narrativas de vida...

JOSSO, M. Experiências de vida e formação. Tradução de José Cláudio e Júlio Ferreira. 2 ed. Natal: EDUFRN, 2010.

KLEIMAN, A. Letramento e suas implicações para o ensino de língua materna. Signo. Santa Cruz do Sul, v. 32, n. 53, p. 1-25, dez. 2007.

KLEIMAN, A. Trajetórias de acesso ao mundo da escrita: relevância das práticas não escolares de letramento para o letramento escolar. Perspectiva, Florianópolis, v. 28, v. 2, p. 375-400, jul./dez. 2010.

KOCH, I. V. G.; ELIAS, V. M. Ler e compreender: os sentidos do texto. 3. ed. São Paulo: Contexto, 2012.

MOITA-LOPES. L. P. Por uma linguística aplicada indisciplinar. São Paulo: Parábola, 2006.

MUSTIFAGA, M. B.; GOETTMS, J. Leitura significativa - prática em todas as disciplinas do currículo escolar. Visão Global, Joaçaba, v. 11, n. 2, p. 195216, jul./dez. 2008.

SERAFIM, M. de S.; CORDEIRO, G. S. A leitura do gênero conto: entendendo as estratégias do leitor. Letras de Hoje, Porto Alegre, v. 48, n. 2, p. 253-261, abr./jun. 2013.

SILVA, E. T. Concepções de leitura e suas consequências no ensino. Perspectiva, Florianópolis, v. 17, n. 31, p. 11-19, jan./jun. 1999.

SOARES, M. Ler, verbo transitivo. In: PAIVA, A.; PAULINO, G.; MARTINS, A. (org.) Leituras literárias: discursos transitivos. Belo Horizonte: Autêntica, 2008.

STREET, B. V. Letramentos sociais: abordagens críticas do letramento no desenvolvimento, na etnografia e na educação. Tradução de Marcos Bagno. 1. ed. São Paulo: Parábola Editorial, 2014.

VASCONCELOS, S. Clínica do Discurso: a arte da escuta. Fortaleza: Premius, 2005. 
Francisco Rogiellyson Andrade; Priscila Lima; Dannytza Gomes

Recebido em: 30/07/2020

Aceito em: 02/12/2020

Title: Reading as a social practice based on the enunciation of life narratives: a case study with a pedagogue teacher 